
\title{
R Reserach S Suare \\ Birth weight is associated with obesity and T2DM in adulthood among Chinese women
}

\section{Pu Song}

Xuzhou Central Hospital

\section{Hui Cao}

Xuzhou Central Hospital

\section{Manqing Yang}

Xuzhou Central Hospital

\section{Peng Lai}

Xuzhou Medical University

Yan Ye

Xuzhou Medical University

Ying Liu

Xuzhou Central Hospital

Xuekui Liu ( $\square$ liuxuekui314@njmu.edu.cn )

Xuzhou Central Hospital https://orcid.org/0000-0003-4523-4225

\section{Research article}

Keywords: Type 2 diabetes, Birth weight, Obesity.

Posted Date: February 9th, 2022

DOI: https://doi.org/10.21203/rs.3.rs-1213418/v1

License: (c) (i) This work is licensed under a Creative Commons Attribution 4.0 International License.

Read Full License 


\section{Abstract}

Background: Previous studies have indicated an association between birth weight (BW) and type 2 diabetes mellitus (T2DM), but few studies have explored this relationship under different conditions of obesity in adulthood.

Methods: A total of 4,005 individuals from ten provinces of China were randomly selected to participate in this study. We used a questionnaire to collect age, BW, current weight, height, T2DM history, age at T2DM diagnosis, and other variables. The participants were divided into three groups were according to BW trisection (BW $\leq 2500 \mathrm{~g}$ for the lower BW group, $2500 \mathrm{~g}<\mathrm{BW} \leq 3500 \mathrm{~g}$ for the normal BW group, and $B W \otimes 3500 \mathrm{~g}$ for the higher BW group). The cutoff of overweight and obesity were $25 \mathrm{~kg} / \mathrm{m}^{2}$ and $28 \mathrm{~kg} / \mathrm{m}^{2}$, respectively.

Results: The prevalence rates of T2DM among women with lower BW, normal BW and higher BW were $5.2 \%, 3.6 \%$ and $2.0 \%$, respectively. The obesity prevalence rates in the lower BW, normal BW and higher BW groups were $8.1 \%, 6.7 \%$ and $9.0 \%$, respectively. In the obese population, we did not find a relationship between BW and T2DM, but in the nonobese population, we found that with increasing BW, the risk of developing T2DM was reduced. Obese status in adulthood modified the association between BW and the risk of T2DM.

Conclusion: There is a " $\mathrm{U}$ " shape association between BW and risk of adulthood obesity in Chinese women, but this trend is not existed between BW and risk of developing T2DM. In non-overweight females, the risk of developing T2DM decreased with increasing BW, but this trend was not observed in overweight females.

\section{Introduction}

The COVID-19 pandemic has caused many problems, such as economic stagnation, high hospital admissions, and other societal issues [1]. Many scientific studies that were not relevant to the prevention and control of COVID-19 were suspended to release more medical staff to flatten the curve of the epidemic. Under these conditions, traditional epidemiological studies faced great difficulty because this field requires face-to-face communication between an investigator and a subject. Such face-to-face communication undoubtedly would increase the chance of COVID-19 transmission [2]. However, social networks can be used to conduct epidemiological investigations because they increase the convenience of communication. In the present study, we used online social software to survey the association between type 2 diabetes mellitus (T2DM) in adulthood and birth weight (BW) among Chinese women.

It is well known that the role of intrauterine nutrition during the fetal period is to ensure the healthy growth of the fetus [3]. Malnutrition or overnutrition during pregnancy may cause harm to the fetus [4]. BW is an index that is used to assess the nutrition status of fetuses [5]. The relationship between BW and T2DM has been noted with concern for many years. Barker and his colleagues reported that BW was associated with impaired glucose tolerance in 1998 [6]. QH Xia [7] found that individuals with low BW $(<2500 \mathrm{~g})$ have 
a higher risk of T2DM (hazard ratio [HR] 1.17) in China. Many academics have indicated that obesity in adulthood may explain the correlation between low BW and T2DM because low BW predisposes individuals to obesity later in life [8]. However, some previous studies found that people with normal BW and higher BW also tend to be obese, and neither positive linear nor $\mathrm{J}$ - or U-shaped associations exist between BW and overweight/obesity in adults $[9,10]$. Although we hypothesized that these inconsistent conclusions may be caused by differences in ethnicity or the environment later in life, this controversial consequence still needs to be verified in different populations. At present, limited evidence has demonstrated the association between BW and obesity or T2DM in the Chinese population, especially among females.

We collected data via social networks to verify the association between BW and the subsequent risk of obesity and T2DM among the Chinse female population and to develop strategies for preventing these diseases.

\section{Methods}

Survey Method. During the COVID-19 pandemic, traditional epidemiological investigations faced a challenge. The freedom of many people was restricted by the government to stop the spread of the virus. Under this condition, we used social software, such as Tiktok and WeChat, to complete our investigation online.

Survey population and questionnaire. Beginning 2018, we employed social software to spread medical knowledge to the general public online, and the health education videos that we made and released on social software were watched a total of 10 million times. Thousands of people contacted us by social software to receive more medical knowledge. These audiences, who have a certain sense of health and good compliance, were candidate populations for this investigation. We randomly recruited 4,200 female participants into the present study. The inclusion criteria of the study were as follows: 1) the subject was at least 18 years old; 2) the subject could operate the software independently; and 3) the individual knew if she had T2DM. The exclusion criteria were as follows: 1 ) the subject had severe liver and kidney diseases; 2) the individual had gestational diabetes mellitus; and 3) the subjects could not complete the survey. We designed a questionnaire to survey the participants. The questionnaire included 18 questions, which covered age, BW, current weight, height, T2DM history, age at T2DM diagnosis, hypertension history, age hypertension diagnosis, etc. Self-reported data were the main data source for this study. The preinvestigation test showed that the Cronbach coefficient was 0.87 .

Patient and Public Involvement. The present study is an observed study, and we recruited participants by social software. Before the recruitment, we have announced the research design on the software. We selected 4,200 female individuals from numerous applicants randomly. No one involved in the recruitment to and conduct of the study except for researchers of this study. Results of this survey will be made into health education videos to spread to participants and the general public. 
Quality Control. We trained the investigators before the survey to ensure the quality of this study. The training content included how to enroll the interviewee online, how to guide the interviewee to complete the questionnaire online, and how to collect the questionnaire online. This survey lasted for four months, from Dec. 2020 to Jun. 2021, and a total of five investigators collected 4,005 questionnaires. A total of 195 participants did not complete the questionnaire because of lost contact. All the completed questionnaires were input into Excel 2016 for analysis.

Statistical analyses. We performed survey analysis with SAS 9.3 for Windows (SAS Institute, Cary, NC) to explore the association between BW and T2DM. Age, current height, current weight and BW are shown as the mean $\pm S D$. The frequency of obesity, hypertension and T2DM is shown as the number (ratio\%). To observe the clinical characteristics of all the individuals, this sample was divided into three groups according to BW level (T1: BW $\leq 2500 \mathrm{~g}$ for the lower BW group, $\mathrm{T} 2: 2500 \mathrm{~g}<\mathrm{BW} \leq 3500 \mathrm{~g}$ for the normal BW group, T3: $>3500 \mathrm{gBW}$ for the higher BW group). The cutoff point of overweight and obesity in these data were $24 \mathrm{~kg} / \mathrm{m}^{2}$ and $28 \mathrm{~kg} / \mathrm{m}^{2}$, respectively [11]. ANOVA was performed to analyze the differences in continuous variables, and the LSD test was used to compare the differences between two groups. Logistic regression was carried out to analyze the association between BW and T2DM. Restricted cubic spline was utilized to show the odds ratio (OR) of BW in patients with different BMI levels. Body mass index (BMI) was estimated by height and weight.

\section{Results}

The clinical characteristic of all individuals. A total of 4,005 Chinese women were ultimately included in the present study to analyze the association between BW and T2DM. The average age was $48.86 \pm 7.99$ years old, and the average BMI was $23.38 \pm 3.28 \mathrm{Kg} / \mathrm{m}^{2}$. The average birth weight of the participants was $3063.61 \pm 461.91 \mathrm{~g}$. A total of $592(14.8 \%)$ individuals suffered from hypertension, 148 (3.7\%) women had T2DM, and 291 (7.3\%) participants were obese. The prevalence rates of T2DM among women with lower BW, normal BW and higher BW were $5.2 \%, 3.6 \%$ and $2.0 \%$, respectively. Compared with individuals with higher BW, individuals with lower BW had a $3.2 \%$ risk of T2DM. The obesity prevalence rates among this study population in the lower BW, normal BW and higher BW groups were $8.1 \%, 6.7 \%$ and $9.0 \%$, respectively. Interestingly, subjects with higher BW had a higher obesity rate and a lower prevalence rate of T2DM, and individuals with lower BW have a higher obesity rate and a higher T2DM prevalence rate. (Table 1) 
Table 1

Bacsic characteristics of participants according to group of BW (Mean \pm SD)

\section{Birth weight(g)}

\begin{tabular}{|c|c|c|c|c|}
\hline Variables & $\begin{array}{l}\text { Lower } \\
\text { BW(<2500g) }\end{array}$ & $\begin{array}{l}\text { Median } \\
\text { BW(2500g 3500g) }\end{array}$ & $\begin{array}{l}\text { Higher } \\
\text { BW( }(₫ 3500 \mathrm{~g})\end{array}$ & Total \\
\hline $\mathrm{n}$ & 743 & 2752 & 510 & 4005 \\
\hline Age(years) & $49.50 \pm 7.55$ & $49.17 \pm 7.85$ & $46.29 \pm 8.86 \dagger$ & $48.86 \pm 7.99$ \\
\hline Height(cm) & $159.83 \pm 5.05$ & $161.07 \pm 4.79 \dagger$ & $162.51 \pm 5.43 \dagger$ & $161.03 \pm 4.98$ \\
\hline Weight(Kg) & $59.33 \pm 9.09$ & $60.69 \pm 8.58 \dagger$ & $62.18 \pm 9.17 \dagger$ & $60.63 \pm 8.79$ \\
\hline BMI & $23.22 \pm 3.42$ & $23.39 \pm 3.19$ & $23.56 \pm 3.55$ & $23.38 \pm 3.28$ \\
\hline Obesity(\%) & $60(8.1 \%)$ & $185(6.7 \%)$ & $46(9.0 \%)$ & $291(7.3 \%)$ \\
\hline $\begin{array}{l}\text { Birth weight } \\
\text { (g) }\end{array}$ & $2394.62 \pm 313.21$ & $3101.29 \pm 195.15 \dagger$ & $3832.07 \pm 277.27 \dagger$ & $3063.24 \pm 461.91$ \\
\hline $\begin{array}{l}\text { Hypertension } \\
(\%)\end{array}$ & $123(16.6 \%)$ & $403(14.6 \%)$ & $66(12.9 \%)$ & $592(14.8 \%)$ \\
\hline $\begin{array}{l}\text { Type } 2 \\
\text { diabetes(\%) }\end{array}$ & $39(5.2 \%)$ & $99(3.6 \%)$ & $10(2.0 \%)$ & $148(3.7 \%)$ \\
\hline
\end{tabular}

The association between BW and obesity, T2DM in Chinese women using restricted cubic spline analyses. Figure $1 \mathrm{~A}$ shows that the association between BW and the risk of developing obesity. When BW at the reference point $(3000 \mathrm{~g})$, there is a " $\mathrm{U}$ " shape existed between BW and obesity. If the participant with BW less than $3000 \mathrm{~g}$, the developing obesity was decreased with increasing BW. On the contrary, If the participant with BW more than $3000 \mathrm{~g}$, the developing obesity was increased with increasing BW ( $P$ value of ANOVA $=0.012, P$ value of non-linear $=0.017)$. Figure 1B shows that the relationship between $B W$ and the risk of developing T2DM. The reference point is $2500 \mathrm{~g}$. There is a linear trend between BW and T2DM $(P$ value for non-linear $=0.331)$. The risk of developing T2DM was decreased with increasing BW.

The association between BW and T2DM in three groups. With the increase in $\mathrm{BW}$, the prevalence rate of T2DM decreased ( $P$ for trend $=0.009$, Table 2 ). After adjusting for age, a trend of statistical significance was observed. After adjusting for BMI and hypertension status, the normal BW group was not significantly different from the lower BW group, but the higher BW group was statistically significant from the lower BW group.(Table 2) 
Table 2

The association between BW and T2DM between three groups.

\begin{tabular}{|lllllll|}
\hline & & \multicolumn{3}{cl}{ Model1 } & \multicolumn{3}{c|}{ Model2 } \\
\hline Tertiles of BW & Non- T2DM & T2DM & OR & $95 \%$ C.I & OR & $95 \%$ C.I \\
\hline Lower BW & 704(94.8\%) & $39(5.2 \%)$ & 1 & 1 & 1 & 1 \\
\hline Median BW & $2653(96.4 \%)$ & $99(3.6 \%)$ & 0.680 & $0.465 \sim 0.995$ & 0.687 & $0.467 \sim 1.011$ \\
\hline Higher BW & $500(98.0 \%)$ & $10(2.0 \%)$ & 0.406 & $0.200 \sim 0.823$ & 0.387 & $0.190 \sim 0.792$ \\
\hline Pfor trend & 0.009 & & 0.006 & & 0.005 & \\
\hline Model1: adjusted Age. & & & & & & \\
\hline Model2: adjusted Age, BMl, Hypertension. & & & & & \\
\hline
\end{tabular}

The association between overweight in adulthood and T2DM in different BW groups. Table 3 shows that compared with the non-overweight population, people with overweight in adulthood have a higher risk of developing T2DM at all BW levels. Patients with lower BW combined with overweight had the highest risk of T2DM.

Table 3

The association between adulthood overweight and T2DM under different BW levels

\begin{tabular}{|c|c|c|c|c|c|}
\hline & & Non-T2DM & T2DM & $x^{2}$ & $P$ \\
\hline \multirow[t]{2}{*}{ Lower BW } & Non-overweight & $481(96.0 \%)$ & $20(4.0 \%)$ & \multirow[t]{2}{*}{4.887} & \multirow[t]{2}{*}{0.027} \\
\hline & Overweight & 223(92.1\%) & $19(7.9 \%)$ & & \\
\hline \multirow[t]{2}{*}{ Median BW } & Non-overweight & 1688(97.6\%) & $42(2.4 \%)$ & \multirow[t]{2}{*}{18.377} & \multirow[t]{2}{*}{$<0.001$} \\
\hline & Overweight & $965(94.4 \%)$ & $57(5.6 \%)$ & & \\
\hline \multirow[t]{2}{*}{ Higher BW } & Non-overweight & $310(99.7 \%)$ & $1(0.3 \%)$ & \multirow[t]{2}{*}{11.141} & \multirow[t]{2}{*}{0.001} \\
\hline & Overweight & $190(95.5 \%)$ & $9(4.5 \%)$ & & \\
\hline
\end{tabular}

Subgroup analysis was used to observe the association between BW and T2DM. In the age subgroups, 35 45-year-old females exhibited a negative association between BW and T2DM. Females with hypertension also exhibited a negative association. In the overweight population, we did not find a relationship between $B W$ and T2DM, but in the non-overweight population, we found that with increased $\mathrm{BW}$, the risk of developing T2DM decreased. (Table 4) 
Table 4

The logistic regression of BW categories and T2DM in different level of factors

\begin{tabular}{|llllll|}
\hline Variables & Beta & Wald & OR & 95\%C.I & $P$ \\
\hline Age(years) & & & & & \\
\hline$<35$ & -0.509 & 2.004 & 0.601 & $0.297 \sim 1.216$ & 0.157 \\
\hline$\geq 35,<45$ & -0.782 & 8.891 & 0.457 & $0.274 \sim 0.765$ & 0.003 \\
\hline$\geq 45,<60$ & -0.011 & 0.001 & 0.989 & $0.441 \sim 2.221$ & 0.979 \\
\hline$\geq 60$ & -0.215 & 0.630 & 0.807 & $0.475 \sim 1.371$ & 0.807 \\
\hline Hypertension & & & & & 0.708 \\
\hline No & -0.345 & 3.151 & 0.708 & $0.484 \sim 1.037$ & 0.021 \\
\hline Yes & -0.584 & 5.323 & 0.558 & $0.340 \sim 0.916$ & 0.004 \\
\hline BMl (kg/m ${ }^{2}$ ) & & & & & 0.197 \\
\hline$<24$ & -0.671 & 8.329 & 0.511 & $0.324 \sim 0.806$ & \\
\hline$\geq 24$ & -0.268 & 1.667 & 0.765 & $0.510 \sim 1.149$ & \\
\hline $\begin{array}{l}\text { Note: the model adjusted age, BMl and hypertension, when the factor was stratified, the factor was } \\
\text { taken out the model. }\end{array}$ & & & & \\
\hline
\end{tabular}

Associations between BW and T2DM varied because of obesity status in adulthood. The figure 2A shows the accumulative T2DM rate in different BW groups, lower BW group have the highest incidence rate of T2DM in three groups $(P=0.009)$. In normal BMI subgroup, the lower BW participants are also given the highest incidence rate of T2DM (Figure 2B, $\mathrm{P}=0.005$ ). In overweight subgroup (Figure $2 \mathrm{C}$ ) and obesity subgroup (Figure 2D), the incidence rate of T2DM were no statistical significance in different BW groups. This result indicated that obese status in adulthood modified the association between BW and the risk of T2DM.

\section{Discussion}

In this study of a sample of Chinese women, we found that there was a significant association between lower BW and an increased risk of T2DM, and BW was associated with the risk of being obesity, with a nonlinear alliance. Subgroup analyses found that the association between BW and T2DM was stronger in the normal BMI adulthood population, and this trend was not observed in individuals who were overweight or obesity in adulthood. Our results not only verified the relationship between BW and T2DM but also found the new argument that being overweight in adulthood can modify the correlation.

Our sample shows that there is a " $\mathrm{U}$ " shape between BW and obesity in adulthood, and the higher BW group had the highest prevalence of obesity in three groups. Some previous studies have found that low 
BW was a risk factor for increased obesity in adulthood. A Chakraborty[12] reported that females with higher socioeconomic status and lower BW had a higher risk of developing obesity (OR $=6.251,95 \% \mathrm{Cl}$ [1.236 31.611]), as well as AR. Bischoff [13] found that school-age girls exhibit a positive correlation between BW and fat intake, and fat accumulation in the body leads to obesity. However, a few scholars found no significant relationship between infant nutritional status, which is usually assessed by BW, and metabolic disease. S A Stanner [9] carried out an epidemiological investigation in 1997 and found that the BMI level in adulthood of a person who was born during a famine period was not different from the BMI level in adulthood of people who were born in a food-rich period. The argument that low BW is related to obesity in adulthood is based on the Thrifty Phenotype Hypothesis (TPH) [14-16], which was proposed by Hales and Barker. The TPH supposed that the fetus in utero must adapt to its environment, especially nutritional deficiencies, to ensure brain growth at the expense of other organs, such as skeletal muscle, pancreas, and kidney [17]. Under this condition, metabolic programming has poor access to nutrition, which can lead to metabolic diseases, such as being overweight and T2DM, later in life [18]. However, another argument suggested that there was a difference in BMI-related genes between Asian and European populations [19-21], and diet differences between Eastern and Western populations were one of the causes of the prevalence of metabolic disease [22,23]. Our results agreed with QH Xia's report [7], which was conducted in Chinese adults, that a higher BW corresponded with a higher prevalence of obesity and that the population with a lower BW had a lower obesity rate. Wang W reported [20]that three BMI-related genes in Asian populations were not found in European populations, and YP Li reported [24] that there was a stronger association between fetal famine exposure and hyperglycemia in Western countries because Western diets contain more meat, sugary and oils [25], which cause obesity when consumed for a long time. Our results indicated that in the BW group, obesity in adulthood was always a risk factor for developing T2DM.

Many previous studies agreed with the present study, as low BW individuals had a higher prevalence of developing T2DM. In adult Inuit populations in Greenland, a study found that BW was inversely associated with hepatic and peripheral insulin resistance [26]. DH M performed a meta-analysis that selected eight studies and found that BW (<2500 g) was associated with an increased risk of T2DM (OR, 1.55; $95 \% \mathrm{Cl}, 1.39 \sim 1.73$ ) [27]. Although TPH provided a probable relationship between low BW and T2DM, the mechanisms underlying the association are not well understood. Metabolomic profiling between individuals with low BW and T2DM found that subjects with low BW had reduced glycolysis and oxidation ability of postprandial glucose, which may be a possible mechanism [28]. Compared with normal infants, babies with low BW have lower adiponectin levels [29], which may be another reason the incidence rate of T2DM increased. The effect of gene-environment interactions on the development of T2DM cannot be ignored. Cohort studies suggested that genetic susceptibility to obesity and low BW combined with unhealthy lifestyles may synergistically affect the risk of T2DM later in life [30]. Intrinsically, females were less sensitive to insulin resistance than males, so they were at particular risk of developing insulin resistance and therefore more susceptible to the development of T2DM [31]. For this reason, we selected females as our sample population. 
The research data of this study were collected by social software online. Compared with traditional epidemiological investigations, the new method of collecting data has some advantages. First, data collected online are not limited to one city or one region. Our sample population was from ten provinces of China. Second, using social software can save time and costs. However, some limitations of this study should be acknowledged. Because of online collection data, most variables in this study were selfreported. Especially the self-reported variable of T2DM, it is estimated that approximately half of all people with T2DM in China remain undiagnosed [32].

\section{Conclusions}

In summary, there is a " $U$ " shape association between BW and risk of adulthood obesity in Chinese women, but this trend is not existed between BW and risk of developing T2DM. In non-overweight females, the risk of developing T2DM decreased with increasing BW, but this trend was not observed in overweight females.

\section{Abbreviations}

BW

birth weight

T2DM

type 2 diabetes mellitus

$\mathrm{BMI}$

Body mass index

OR odds ratio.

\section{Declarations}

\section{Ethics approval and consent to participate}

The study was reviewed and approved by the ethics committee of the Xuzhou central hospital. The NO. of ethics committee approval is XZXY-LJ-20201110-060. All participants were signed an informed consent form on-line before investigating.

\section{Consent for publication}

Not Applicable.

\section{Availability of data and materials}

All data generated or analyzed during this study are included in this manuscript. 
All authors declare that there is no duality of interest associated with this manuscript.

\section{Funding}

This work was supported by the Xuzhou Municipal Science and Technology Bureau (KC21208). The funder-XK L- is responsible for the integrity of the work as a whole.

\section{Author's contribution}

$P S, M Q Y$ and $Y L$ were drafted this manuscript. P S, H C, Y Y, XK L took part in the collection of data. XK

$L$ and $P L$ analyzed the data. $X K L$ is responsible for the integrity of the work as a whole.

\section{Acknowledgements}

We acknowledge and thank all participants for their cooperation and sample contributions.

\section{References}

1. Diptyanusa A, Zablon KN. Addressing budget reduction and reallocation on health-related resources during COVID-19 pandemic in malaria-endemic countries. Malar J. 2020;19(1):411.

2. Cárdenas-González M, Álvarez-Buylla ER. The COVID-19 Pandemic and Paradigm Change in Global Scientific Research. MEDICC Rev. 2020;22(2):14-8.

3. Haschke F, Binder C, Huber-Dangl M, Haiden N. Early-Life Nutrition, Growth Trajectories, and LongTerm Outcome. Nestle Nutrition Institute workshop series. 2019;90:107-20.

4. Pari-Keener M, Gallo S, Stahnke B, McDermid JM, Al-Nimr RI, Moreschi JM, Hakeem R, Handu D, Cheng FW. Maternal and Infant Health Outcomes Associated with Medical Nutrition Therapy by Registered Dietitian Nutritionists in Pregnant Women with Malnutrition: An Evidence Analysis Center Systematic Review. Journal of the Academy of Nutrition Dietetics. 2020;120(10):1730-44.

5. Woldeamanuel GG, Geta TG, Mohammed TP, Shuba MB, Bafa TA: Effect of nutritional status of pregnant women on birth weight of newborns at Butajira Referral Hospital, Butajira, Ethiopia. SAGE open medicine 2019, 7:2050312119827096.

6. Ravelli AC, van der Meulen JH, Michels RP, Osmond C, Barker DJ, Hales CN, Bleker OP. Glucose tolerance in adults after prenatal exposure to famine. Lancet. 1998;351(9097):173-7.

7. Xia Q, Cai H, Xiang YB, Zhou P, Li H, Yang G, Jiang Y, Shu XO, Zheng W, Xu WH. Prospective cohort studies of birth weight and risk of obesity, diabetes, and hypertension in adulthood among the Chinese population. J Diabetes. 2019;11(1):55-64.

8. Silverwood RJ, Pierce M, Hardy R, Sattar N, Whincup P, Ferro C, Savage C, Kuh D, Nitsch D. Low birth weight, later renal function, and the roles of adulthood blood pressure, diabetes, and obesity in a British birth cohort. Kidney Int. 2013;84(6):1262-70.

9. Stanner SA, Bulmer K, Andrès C, Lantseva OE, Borodina V, Poteen VV, Yudkin JS. Does malnutrition in utero determine diabetes and coronary heart disease in adulthood? Results from the Leningrad siege 
study, a cross sectional study. BMJ. 1997;315(7119):1342-8.

10. Zhao Y, Wang SF, Mu M, Sheng J. Birth weight and overweight/obesity in adults: a meta-analysis. Eur J Pediatr. 2012;171(12):1737-46.

11. Chen XY, Wu ZF, Wang XC, Dong XL, Zhu JF, Chen T, Xiao QW, Jiang ZW, Fu C. [Association between body mass index and its change and type 2 diabetes mellitus risk in a prospective study]. Zhonghua liu xing bing xue za zhi. 2016;37(10):1332-5.

12. Chakraborty A, Rakesh PS, Kumaran V, Prasad J, Alexander AM, George K. Risk of developing adulthood obesity among females born with low birth weight: Results from a non-concurrent study from rural Southern India. Indian J Endocrinol Metab. 2014;18(3):414-8.

13. Bischoff AR, Portella AK, Paquet C, Dalle Molle R, Faber A, Arora N, Levitan RD, Silveira PP, Dube L. Low birth weight is associated with increased fat intake in school-aged boys. Br J Nutr. 2018;119(11):1295-302.

14. Hales CN, Barker DJ. Type 2 (non-insulin-dependent) diabetes mellitus: the thrifty phenotype hypothesis. Diabetologia. 1992;35(7):595-601.

15. Hales CN, Barker DJ. The thrifty phenotype hypothesis. British medical bulletin. 2001;60:5-20.

16. Siddiqui K, Joy SS, Nawaz SS. Impact of Early Life or Intrauterine Factors and Socio-Economic Interaction on Diabetes - An Evidence on Thrifty Hypothesis. Journal of lifestyle medicine. 2019;9(2):92-101.

17. Prentice AM, Rayco-Solon P, Moore SE: Insights from the developing world: thrifty genotypes and thrifty phenotypes. The Proceedings of the Nutrition Society 2005, 64(2):153-161.

18. Petry CJ, Ozanne SE, Hales CN. Programming of intermediary metabolism. Mol Cell Endocrinol. 2001;185(1-2):81-91.

19. Chen P, Takeuchi F, Lee JY, Li H, Wu JY, Liang J, Long J, Tabara Y, Goodarzi MO, Pereira MA, et al. Multiple nonglycemic genomic loci are newly associated with blood level of glycated hemoglobin in East Asians. Diabetes. 2014;63(7):2551-62.

20. Wen W, Zheng W, Okada Y, Takeuchi F, Tabara Y, Hwang JY, Dorajoo R, Li H, Tsai FJ, Yang X, et al. Meta-analysis of genome-wide association studies in East Asian-ancestry populations identifies four new loci for body mass index. Human molecular genetics. 2014;23(20):5492-504.

21. Liang J, Sun Y, Liu X, Zhu Y, Pei Y, Wang Y, Qiu Q, Yang M, Qi L. Genetic predisposition to obesity is associated with insulin secretion in Chinese adults: The Cardiometabolic Risk in Chinese (CRC) study. J Diabetes Complications. 2016;30(7):1229-33.

22. Fabiani R, Naldini G, Chiavarini M. Dietary Patterns and Metabolic Syndrome in Adult Subjects: A Systematic Review and Meta-Analysis. Nutrients 2019, 11(9).

23. Pawelzik SC, Bäck M. Eastern Remedies for Western-type diet induced atherosclerosis. Annals of translational medicine. 2020;8(6):258.

24. Li Y, He Y, Qi L, Jaddoe VW, Feskens EJ, Yang X, Ma G, Hu FB. Exposure to the Chinese famine in early life and the risk of hyperglycemia and type 2 diabetes in adulthood. Diabetes. 2010;59(10):2400-6. 
25. Berk KA, Yahya R, Verhoeven AJM, Touw J, Leijten FP, van Rossum EF, Wester VL, Lips MA, Pijl H, Timman R, et al. Effect of diet-induced weight loss on lipoprotein(a) levels in obese individuals with and without type 2 diabetes. Diabetologia. 2017;60(6):989-97.

26. Ronn PF, Jorgensen ME, Smith LS, Bjerregaard P, Dahl-Petersen IK, Larsen CVL, Grarup N, Andersen GS. Associations between birth weight and glucose intolerance in adulthood among Greenlandic Inuit. Diabetes Res Clin Pract. 2019;150:129-37.

27. Mi D, Fang H, Zhao Y, Zhong L. Birth weight and type 2 diabetes: A meta-analysis. Exp Ther Med. 2017;14(6):5313-20.

28. Ivorra C, García-Vicent C, Chaves FJ, Monleón D, Morales JM, Lurbe E. Metabolomic profiling in blood from umbilical cords of low birth weight newborns. Journal of translational medicine. 2012;10:142.

29. Stocker C, O'Dowd J, Morton NM, Wargent E, Sennitt MV, Hislop D, Glund S, Seckl JR, Arch JR, Cawthorne MA. Modulation of susceptibility to weight gain and insulin resistance in low birthweight rats by treatment of their mothers with leptin during pregnancy and lactation. International journal of obesity related metabolic disorders: journal of the International Association for the Study of Obesity. 2004;28(1):129-36.

30. Qie R, Han M, Huang S, Li Q, Liu L, Zhang D, Cheng C, Zhao Y, Liu D, Qin P, et al. Association of TCF7L2 gene polymorphisms, methylation, and gene-environment interaction with type 2 diabetes mellitus risk: A nested case-control study in the Rural Chinese Cohort Study. J Diabetes Complications. 2021;35(3):107829.

31. Knop MR, Geng TT, Gorny AW, Ding R, Li C, Ley SH, Huang T. Birth Weight and Risk of Type 2 Diabetes Mellitus, Cardiovascular Disease, and Hypertension in Adults: A Meta-Analysis of 7646267 Participants From 135 Studies. J Am Heart Assoc. 2018;7(23):e008870.

32. Yang W, Lu J, Weng J, Jia W, Ji L, Xiao J, Shan Z, Liu J, Tian H, Ji Q, et al. Prevalence of diabetes among men and women in China. N Engl J Med. 2010;362(12):1090-101.

\section{Figures}

\section{Figure 1}

The association between birth weight and obesity (Figure 1A), and the relationship between birth weight and T2DM (Figure 1B) in Chinese women. (HR: hazard ratio, T2DM: Type 2 diabetes mellitus). ANOVA was performed to analyze the risk of obesity or T2DM in different BW levels. Our resluts show that BW is a risk factor of obesity or T2DM in Chinese women. The non-linear test was used to the variation trend of HR. We found there is a linear trend between BW and risk of developing T2DM (Figure 1B), and a nonlinear trend existed BW and obesity (Figure 1A). 


\section{Figure 2}

The accumulative incidence rate of T2DM in three groups under the total and different obese status.

Figure 2A shows lower BW group has the highest incidence rate of T2DM in three groups, and Figure 2B shows lower BW group has the highest incidence rate of T2DM in three groups under non-overweight or obesity status too. Under the overweight or obesity status, although lower BW group has a higher incidence rate of T2DM, there is no statistical significance. 